\title{
LOGISTICS PERFORMANCES OF GULF COOPERATION COUNCIL'S COUNTRIES IN GLOBAL SUPPLY CHAINS
}

\author{
Ilija Stojanović ${ }^{1}$ and Adis Puška ${ }^{2}$
}

\author{
${ }^{1}$ College of Business Studies, Al Ghurair University, Dubai, United Arab Emirates \\ ${ }^{2}$ Institutes for Scientific Research and Development, Brčko District, Bosnia and \\ Herzegovina
}

Received: 10 January 2021;

Accepted: 7 March 2021;

Available online: 13 March 2021.

Original scientific paper

\begin{abstract}
Regional integration into the Gulf Cooperation Council has enabled respective countries to effectively participate in global supply chains. To ensure effective integration of this region into global supply chains, logistics operations are a very important determinant. The aim of this study was to assess logistical performances of GCC countries, and to identify which country has the best conditions for establishing a regional logistic center. For this study, we used relevant data from Logistics Performance Index (LPI) developed by the World Bank. The research was conducted using a hybrid multi-criteria approach based on the CRITIC and MABAC methods. The findings of this study indicate that the United Arab Emirates has the best conditions for establishing a regional logistics center. This study also releveled the areas of logistics in which other GCC countries should make an improvement to improve their logistical performance.
\end{abstract}

Keywords: Logistics center; logistics performance; global supply chains; GCC countries; multi-criteria analysis.

\section{Introduction}

Global competitive pressure is forcing countries to strengthen their position in the world market through regional integration. With trade and customs agreements individual countries have been enabled to improve their competitive position within a single regional market towards other regions and countries globally. This was also the incentive for the Gulf countries to establish a Cooperation Council for the Arab States of the Gulf in 1981, also known as Gulf Cooperation Council (GCC), composed by Bahrain, Kuwait, Oman, Qatar, Saudi Arabia, and the United Arab Emirates. Gulf integration has enabled facilitation of the movement of production, removing trade barriers, and coordinating economic policies, extending the size of the market for the estimated 35.65 million inhabitants who live in this region (Fernandes and Rodrigues, 
Logistics Performances of Gulf Cooperation Council's Countries in Global Supply Chains 2009). Moreover, it has created the preconditions for establishment of supply chains with the aim of joint GCC exposure on the global market.

According to the Statistical Centre for the Cooperation Council for the Arab Countries of the Gulf (GCC-Stat), total export of GCC countries was around 652 billion of USD in 2018 and rising. Well known fact is that oil export is one of the key trade operations, but many other products take an important role in export activities of the GCC region. Having this in mind, Durugbo et al. (2020) pointed out the strategic global importance for supply chains for these countries. These scholars found that supply chains in the GCC region confront 3 main complexity management challenges including "strategically selecting and integrating network resources', 'reliably contracting and delivering high-quality solutions', and 'cost effectively controlling and financing operational expansions" (Durugbo et al., 2020, p.13). They also proposed to GCC-based companies to work closely in enabling optimization of their export activities to maximize competitiveness and minimize operational risks and uncertainty.

To create an effective supply chain, appropriate logistics operations are crucial. According to Christopher (2017, p.4), "effective logistics and supply chain management can provide a major source of competitive advantage". Having in mind global market game and the necessity of GCC countries to be included effectively into global supply chains, we focused our academic curiosity to logistical performances of GCC countries. Our main goal of this study is to see which GCC country provides the best conditions in terms of logistics to enable the GCC region to be effectively included into global supply chains. This study provides insight into areas of logistics for each GCC country where improvement is needed to enable more effective logistics operations.

The selection of the logistics center was done using the Logistics Performance Index (LPI) data developed by the World Bank for the time periods 2012, 2014, 2016 and 2018. With the purpose of ranking GCC countries from their logistics performance, a combination of CRITIC (criteria importance through intercriteria correlation) and MABAC (multi-attributive border approximation area comparison) were applied. The CRITIC method was used to determine the weight of the criteria in an objective way, while the MABAC method was used to rank these countries. This approach allowed determination which of the GCC countries has the best characteristics in LPI over different time periods. This approach addressed the following questions:

a) Can combinations of MCDA methods be used when choosing a logistics center?

b) Does the ranking of the GCC countries differ throughout different time periods?

c) Which of the GCC countries has the best LPI characteristics to be proposed for a joint logistics center?

The contribution of this approach one can be found in the new way of ranking countries for other regions to determine those with the best LPI characteristics. Thus, this study has paved the way for future investigation with the similar approach in other regions with the aim of selecting the logistics center's best location according to the country's logistics performances.

In addition to the introduction section, this paper is organized as follows. Section two is intended for literature review. In the third section the research methodology is explained, and the MCDA methods to be used in this study. The fourth section is intended for research results and for the analysis of the obtained results. The fifth 
section is focused to discuss the obtained results, while the sixth selection is intended to conclude the obtained research results.

\section{Literature review}

Global competition is a major characteristic of today's marketplace where the race for a better position is constant. This is not only the race between companies, but also between countries that need constantly to evaluate their competitive position (Önden at al., 2018). Modern time is also characterized with dramatic increase in trade across borders (Akkermans at al., 1999). According to Kishore and Padmanabhan (2016), globalization and global competition indicate the great importance of the logistics industry. However, Klassen and Whybark (1994), based on their study, found that the complexity of global logistics is one of key barriers to the effective management of international operations.

With globalization, global supply chains become highly significant. „Global supply chains are a mechanism by which firms can achieve a competitive advantage" (Sundarakani at al., 2012, p.2). According to Reyes et al. (2002), perceptive firms are increasingly pursuing global supply chain operations to reduce costs. Some scholars identify some differences between logistics and supply chains (Larson and Halldorsson, 2004). According to Memedovic et al. (2008, p. 355), "logistics commonly refers to organizing and coordinating the movements of material inputs, final goods and their distribution."

Pham et al. (2017) argue that logistics is an important element of supply chains, putting focus especially on logistics centers. We especially emphasize the claim by Stević et al. (2015), that logistical centers are key elements of logistical network. According to their opinion, the entire logistics system relies on logistics centers that have integrative function within logistics systems. Zaralı and Yazgan (2016) highlighted that logistics centers have key roles in streaming transport operation at national and international level; the selection of their position is of particular importance for their effectiveness and efficiency.

One of the most rapid developing world regions by increasing worldwide circulation of commodities is the region of Gulf Cooperation Council (GCC) countries which become a central node in global trade (Ziadah, 2018). This region is composed by six Araab countries: The Kingdoms of Bahrain and Saudi Arabia, the Sultanate of Oman, the States of Kuwait and Qatar, and the United Arab Emirates. Durugbo et al. (2020) estimated that this region accounts for around 30\% of the globally known oil reserves. The GCC region also has strategic geographic position along the Asia-Europe trade route. According to Ziadah (2018), authorities in this region have recognized the possibility of economic diversification by making huge investments into logistics infrastructure: maritime ports, roads, rail, airports and logistics cities, and yet is to come from GCC development plans. Fernandes and Rodrigues (2009) particularly emphasized the importance of Special Economic Zones that have been established as an instrument to boost employment, export, and foreign exchange. According to them, countries within this region are positioning themselves to be logistic hubs by strengthening transport, and connectivity, and this can lead to attracting foreign investments.

Durugbo et al. (2020) provided great insight into the existing literature of the supply chain management of the GCC region and found high levels of complexity and uncertainty within this regional business environment. One of the complexities found by these authors is related to strategically selecting and integrating network resources 
Logistics Performances of Gulf Cooperation Council's Countries in Global Supply Chains

within the GCC region, focusing attention on the views of multinational companies towards regional supply chains. According to these authors, those multinational companies located in the GCC region are very focused on regional supply chains.

According to Memedovic et al. (2008), oil-producing countries, with exception of the United Arab Emirates and Bahrain, perform below their potential and their logistics systems usually focus on their main export commodities rather than focusing on diversification on trade logistics. These authors pointed to an example of Dubai Ports World that has become one of the most important global port operators, operating 42 port terminals in 27 countries. Memedovic at al. (2008) also pointed out that countries with better logistics capabilities can attract more foreign direct investments, decrease transaction costs, diversify export structure, and have higher growth.

Very important issues in managing logistics operations arise among scholars. One of these issues, as stated by Akkermans et al. (1999) is related to managing good flows between facilities in a chain of operations, thus putting focus on the importance of coordinated planning approach that can reduce costs. Several scholars warned of the need to have an appropriate coordination in decision making on the design of international facility networks (Scully and Fawcett, 1993; Meijboom and Vos, 1997). Coe at al. (2004) argued that with establishment of the global commodity chain approach, the importance of regions in economic activities arises.

Önden et al. (2018) argued that the location of the logistics centers is a key element of the transport system and location decisions should be done strategically. Otherwise, opposite decisions could increase costs and create transport bottlenecks. However, due to undoubted advantages for the economy, regional authorities want their region to be considered for logistical centers and this could lead to rising logistics costs, increasing travel distances by trucks, and lacking multi-modal transportation possibilities. After analyzing the situation in the GCC region, Ziadah (2018) found a large degree of duplication in port infrastructure in this part of the world. Thus, analyzing which country in the GCC region provides the highest benefit for the economy of the region is fully justified and we are going to do this with this study. This is especially important due to the necessity to build long-term relationships between regions, which are according to Li et al. (2011) critical factor to establish a successful logistics system.

Complex system of global value chains is dependent on efficient logistics (Memedovic et al., 2008). Thus, location of logistics centers has become an imperative of logistics and supply chain management because it contributes to the efficiency of supply chain (Rao et al., 2015). Memedovic et al. (2008) argued that characteristics of each supply chain logistics will affect decisions about the advantages and disadvantages of different locations, and especially costs, transport access, business environment for round-the-clock operations leads to a variety of location strategies.

Having in mind a trend of moving production in different global regions, this has affected changes in global distribution systems. According to Coe et al. (2004), preferred locations for building large distribution centers became gateways and corridors with access to traditional trade gateways and to large consumer markets. Based on this notion of the importance of location, these scholars highlighted the importance of enabling competitive logistics services at low rates. Fernandes and Rodrigues (2009) also argued that staying competitive for companies implies a strategy by which parts of the value chain are in countries where they can take advantage of lower costs due to location factors. At the same time, according to these scholars, companies search for multimodal hubs to optimize the cost efficiencies of sea freight with that of quicker but expensive air freight. 
Martí et al. (2017) highlighted that international trade has been affected by increased competitiveness of lagged regions that in the past did not play such an important role in the world. Thus, they believe that only those countries prepared to implement the advances that commercial globalization requires can benefit from improved logistics performance. According to Chow et al. (1994), measurement of performance must recognize the role of an organization in a supply chain. Önden et al. (2018) pointed out that logistics performance is an accelerator of the competitiveness of a country and thus, they need to evaluate their position using various indicators including logistics performance index (LPI). Memedovic et al. (2008) indicated the usefulness of LPI as a composite index which shows that building the logistics capacity to connect firms, suppliers and consumers is even more important today than costs. Thus, within logistics performance analysis for GCC countries we will use LPI data. Biswas and Anand (2020) performed a very interesting comparative analysis of the G7 and BRICS countries on the basis of logistical competitiveness, and they expanded the criteria by using the adoption of information and communication technologies and $\mathrm{CO}_{2}$ intensity in addition to the LPI criteria.

A very good insight in the literature dealing with the issue of selecting the best location of the logistics center was given by Uyanik et al. (2018) who analyzed 35 different studies with the location selection problem. They found that different methods were applied by different authors, but what they found as common ground across these studies is that the selection decision was based on a different number of criteria by using Multi-Criteria Decision-Making Models. Kuo (2011) used ten selection criteria including port rate, import/export volume, location resistance, extension transportation convenience, transshipment time, one stop service, information abilities, port \& warehouse facilities, port operation system, and density of shipping line, while $\mathrm{Ou}$ and Chou (2009) used six factors named valued added service, transportation and distribution systems, market potential, environment, infrastructure and culture to identify international distribution center from a foreign market perspective. Elevli et al. (2014) believed that decision makers for selecting locations of logistic centers prefer to pursue more than one goal or consider more than one factor. This is where the justification for use of multi-criteria decision analysis with fuzzy logic lies.

Very significant studies can be found in the literature that deal with the problem of selection of logistics centers using multi-criteria decision analysis with fuzzy logic. Kishore and Padmanabhan (2016) argued that the fuzzy approach is capable of capturing vagueness associated with subjective perception of decision makers. Li et al. (2011) analyzed among 15 regional logistics center cities and thirteen criteria to identify logistics center location, and they used linguistic variables instead of numerical values in this study applying fuzzy-set theory. These scholars believed that linguistic variables are more appropriate when performance values cannot be expressed with numerical values. Elevli (2014) used Fuzzy Preference Ranking Organization METHod for Enrichment Evaluation. This method combined the concept of fuzzy sets to represent uncertain information with the PROMETHEE. Kazançoğlu et al. (2019) applied sustainability benchmarking principles by using hybrid multicriteria decision-making method, fuzzy AHP and PROMETHEE methods in the selection process. Sun et al. (2019) explored location problems in a three-stage logistics network that consists of suppliers, logistics centers, and customers and they put focus on the environmental sustainability. For their study, they applied two fuzzy mixed integer linear programming models. Phamb et al. (2017) developed a benchmarking framework for selection of logistics centers by applying a hybrid of the 
Logistics Performances of Gulf Cooperation Council's Countries in Global Supply Chains

fuzzy method and the technique for order of preference by similarity to ideal solution (TOPSIS). They found that freight demand, closeness to market, production area, customers, and transportation costs are most important factors for selection. Biswas and Anand (2020) applied the PIV (Proximity Indexed Value) method and the TOPSIS method to perform a comparative analysis of the G7 and BRICS countries. With their study, Wang et al. (2010) put their focus in selection of locations that maximize profits and minimize costs. They established a fuzzy multiple criteria decision-making model based on fuzzy AHP for the LDC assessment. Few years later, Wang et al. (2014) focused on the consistency and the historical assessments accuracy by introducing priority of consistency and historical assessments accuracy mechanism into a fuzzy multi-criteria decision making approach. Focusing on several criteria, such as proximities to highway, railway, airports, and seaports; volume of international trade; total population; and handling capabilities of the ports, Önden et al. (2018) combined the fuzzy analytic hierarchy process, spatial statistics and analysis approaches to evaluate suitable level for logistics center. One of most interesting studies we found in the literature is delivered by Stević et al. (2015) who searched for the best location of logistics centers throughout the state of different facts important for selection of the best location. They used the AHP method of multi-criteria analysis.

Our research problem is focused on analyzing logistics performance of GCC countries to identify which country can provide the best logistical conditions to make this region even stronger within global supply chains.

\section{Methodology}

The identification of the most suitable location for the logistic center in this study was conducted at the first step with the analysis of logistic performances of selected countries. In this study, the identification of logistic center location was performed using a hybrid multi-criteria approach based on the CRITIC and MABAC methods. The selected countries that were examined under this study included 6 countries from the Gulf Cooperation Council: Bahrain, Kuwait, Oman, Qatar, Saudi Arabia, and the United Arab Emirates (UAE). To assess logistical performances of selected GCC countries, we used relevant data from the Logistics Performance Index (LPI) developed by the World Bank. Based on the LPI, the following indicators were taken into consideration: Customs, Infrastructure, Services, Timeliness, Tracking and tracing and International shipments (Table 1).

During the research, the following steps were conducted:

1. Data collection

2. Forming of decision matrix

3. Determining weights for criteria

4. Ranking of GCC countries

5. Analysis of the results 
Stojanović and Puška/Decis. Mak. Appl. Manag. Eng. 4 (1) (2021) 174-193

Table 1. Core components of LPI

\begin{tabular}{|c|c|c|}
\hline & Component & Definition \\
\hline C1 & Customs & $\begin{array}{l}\text { The efficiency of customs and border management } \\
\text { clearing. }\end{array}$ \\
\hline $\mathrm{C} 2$ & Infrastructure & The quality of trade and transport infrastructure. \\
\hline $\mathrm{C} 3$ & Services & The competence and quality of logistics services. \\
\hline $\mathrm{C} 4$ & Timeliness & $\begin{array}{l}\text { The frequency with which shipments reach } \\
\text { consignees within expected delivery times. }\end{array}$ \\
\hline C5 & Tracking and tracing & The ability to track and trace consignments. \\
\hline C6 & $\begin{array}{l}\text { International } \\
\text { shipments }\end{array}$ & $\begin{array}{l}\text { The ease of arranging competitively priced } \\
\text { shipments }\end{array}$ \\
\hline
\end{tabular}

Source: World Bank

The first step of this research was data collection. For this study we collected data from the Logistic Performance Indicators (LPI) from the World Bank available from the website: lpi.worldbank.org. To obtain the most complete data on LPI trends for GCC countries, data for the years 2012, 2014, 2016 and 2018 were used.

After the data were collected, a decision matrix is formed for the specified periods and selected countries. Having in mind that we used data from 4 different periods, we formed five decision matrices to enable further analysis. These decision matrices are the basis for implementing methods for multi-criteria data analysis.

The next step was to determine the importance of the used criteria. Before we made rankings of selected countries, it was necessary to determine the importance of the criteria. In order to eliminate subjectivity in ranking of selected countries, the CRITIC method was used to determine the weights of the criteria. The CRITIC method has an approach to objectively calculate weight values based on standard deviation values and correlation coefficients. Since we used data for four time periods, the weights for each of these decision matrices were calculated and reconciled. Adjustment was done by applying the average value of the weights. These average values were used to rank GCC countries in terms of logistic center selection.

After the initial decision matrix was formed and the weights of the criteria were calculated, the GCC countries were ranked in relation to the LPI. Ranking was done using the MABAC method. The results in previous studies obtained using the MABAC method have shown that this method can be used as a support in decision making (Božanić, et al., 2016) and in the ranking of alternatives (Pamučar and Ćirović, 2015). First, the data were normalized, then the normalized decision matrix was weighted, and the determination of the approximate border area matrix was calculated. Following these steps, the alternatives were placed in relation to the value of the approximate border area, following with ranking of the alternatives. More details about the CRITIC and MABAC method are shown below. The ranking of alternatives was done for all selected time periods.

After the selected countries were ranked, it was necessary to analyze the research results. The analysis of research results was applied in two ways. First, the results obtained by the MABAC method were analyzed and compared with the results obtained by applying other methods of multi-criteria analysis. After confirming the results obtained by the MABAC method, a sensitivity analysis was conducted. Sensitivity analysis examines the extent to which a criterion has an impact on the ranking of alternatives. Sensitivity analysis and comparison of results was performed for all time periods to get a complete insight of the LPI performance of GCC countries. 
Logistics Performances of Gulf Cooperation Council's Countries in Global Supply Chains

\subsection{CRITIC method}

The CRITIC method was developed by Diakoulaki, et al. (1995). This method serves to determine the objective values of the criteria weight, which includes the intensity of contrast and conflict that is contained in the structure of the decision problem (Puška, et al., 2018). To determine the contrast of criteria, the standard deviations of the standardized values of the variants per column are used, as well as the correlation coefficients of all pairs of columns. The steps in implementing the CRITIC method are as follows:

Step 1. Defuzzification of the initial decision matrix. Before the other steps of the CRITIC method are performed, fuzzy numbers need to be converted to numerical values (Kiani Mavi, et al., 2016). Defuzzied is performed using the following expression:

$P(\tilde{m})=\frac{1}{6}\left(m_{1}+4 x m_{2}+m_{3}\right)$

where $m_{1}$ is the first value of fuzzy number, $m_{2}$ is the second value of fuzzy number and $m_{3}$ is the third value of fuzzy number.

Step 2. Normalization of the defuzzied initial decision matrix using the following expressions:

For criteria to be maximized:

$r_{i j}=\frac{x_{i j}-x_{r}^{* *}}{x_{j}^{*}-x_{j}^{* *}}$

For criteria to be minimized:

$r_{i j}=1-\frac{x_{i j}-x_{r}^{* * *}}{x_{j}^{*}-x_{j}^{* * *}}$

where: $x_{j}^{*}$ - the maximum value of the feature for a given criterion, $x^{* *}{ }_{j}$ - the minimum value of the feature for a given criterion.

Step 3. Calculation of the values of the standard deviation and the symmetric linear correlation matrix of all pairs per column.

Step 4. Determination of the amount of information using the following expression.

$C_{j}=\sigma_{j} \sum_{k=1}^{m}\left(1-r_{j k}\right) j=\overline{1, m}$

where $\sigma_{j}$ standard deviation of criteria and $r_{j k}$ correlation coefficient for criteria.

Step 5. Calculation of the final values using the following expression:

$w_{j}=\frac{C_{j}}{\sum_{j=1}^{m} C_{j}}$

\subsection{MABAC method}

The MABAC method was developed by Pamučar and Ćirović (2015). The basic assumption of the MABAC method is reflected in the definition of the distance of the alternative from the boundary approximate domain. The boundary approximate area represents the average value for all alternatives. If the alternative is above that value, its value will be positive and vice versa. The MABAC method consists of the several steps.

Step 1. Construct the initial decision matrix. As a first step, $m$ alternatives are evaluated according to $n$ criteria. The alternatives are represented with vectors $A_{i}=$ $\left(x_{i 1}, x_{i 2}, \ldots, x_{i n}\right)$, where $x_{i j}$ is the value of $i$ alternative by $j$ criterion $(i=1,2, \ldots, m ; j=1,2, \ldots, n)$. 
Step 2. Normalization of the elements of the initial matrix. The elements of the initial decision matrix are normalized by the following expressions:

For benefit-type criteria:

$t_{i j}=\frac{x_{i j}-x_{i}^{-}}{x_{i}^{+}-x_{i}^{-}}$

For cost-type criteria:

$t_{i j}=\frac{x_{i j}-x_{i}^{+}}{x_{i}^{-}-x_{i}^{+}}$

where is $x_{i}^{-}$represents minimum values of the left distribution offuzzy numbers of the observed criterion by alternatives, and $x_{i}^{+}$represent the maximum values of the right distribution of fuzzy numbers of the observed criterion by alternatives.

Step 3. Calculation of the weighted matrix (V) elements (Božanić, et al, 2019).

$\tilde{v}_{i j}=w_{i} \cdot \tilde{t}_{i j}+w_{i}$

Where $w_{i}$ represents the weighted coefficients of the criterion.

Step 4. Determination of the approximate border area matrix $(G)$.

$g=\left(\prod_{j=1}^{m} \tilde{v}_{i j}\right)^{1 / m}$

where $m$ represents total number of alternatives

Step 5. Calculation of the matrix elements of alternatives distance from the border approximate area. The distance of the alternatives from the border approximate area $\left(\tilde{q}_{i j}\right)$ is defined as the difference between the weighted matrix elements (V) and the values of the border approximate areas $(\mathrm{G})$.

$\tilde{Q}=\tilde{V}-\tilde{G}$

Now, border approximation area value for each criteria function serves as reference point/benchmark value for criteria-wise performance of an alternative $A_{i}$. Each individual candidate will belong to three different areas namely, the border approximation area $(G)$, upper approximation area $\left(G^{+}\right)$, and lower approximation area $\left(G^{-}\right)$. The ideal alternative $\left(A_{i}^{+}\right)$can be found in the upper approximation area $\left(G^{+}\right)$whereas the lower approximation area $\left(G^{-}\right)$contains the anti-ideal alternative $\left(A_{i}^{-}\right)$(Božanić, et al., 2016).

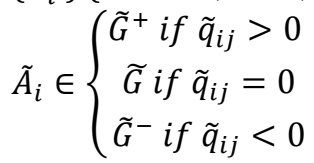

For an alternative $A_{i}$ to be chosen as the best from the set, it is necessary for it to belong, by as many as possible criteria, to the upper approximate area $\left(\tilde{G}^{+}\right)$. The higher the value $\tilde{q}_{i} \in \tilde{G}^{+}$indicates that the alternative is closer to the ideal alternative, while the lower the value $\mathrm{q} \tilde{q}_{i} \in \tilde{G}^{-}$indicates that the alternative is closer to the anti-ideal alternative.

Step 6 Ranking of alternatives. The calculation of the values of the criteria functions by alternatives is obtained as the sum of the distance of alternatives from the border approximate areas $\left(\tilde{q}_{i}\right)$. By summing up the matrix $\widetilde{Q}$ elements per rows, the final values of the criteria function of alternatives are obtained $\tilde{S}_{i}=\sum_{j=1}^{n} \tilde{q}_{i j}, j=1,2, \ldots, n, i=1,2, \ldots, m$

\section{Results}

Before we ranked GCC countries according to LPI indicators, it was necessary to form an initial decision matrix. The initial decision matrix is presented in Table 2 . The 182 
Logistics Performances of Gulf Cooperation Council's Countries in Global Supply Chains LPI data for GCC countries are comparable from the most recent data to the data from previous years. After the initial decision matrices for the observed time periods have been formed (Table 2), the steps of the CRITIC and MABAC methods were performed. The example of data from 2018 explains the way in which GCC countries are ranked.

Table 2. LPI indicators for GCC countries in the period 2010-2018

\begin{tabular}{|c|c|c|c|c|c|c|c|c|c|c|c|c|}
\hline \multirow[b]{2}{*}{ Country } & \multicolumn{6}{|c|}{2018} & \multicolumn{6}{|c|}{2016} \\
\hline & $\mathrm{C} 1$ & $\mathrm{C} 2$ & $\mathrm{C} 3$ & $\mathrm{C} 4$ & $\mathrm{C} 5$ & $\mathrm{C} 6$ & $\mathrm{C} 1$ & $\mathrm{C} 2$ & $\mathrm{C} 3$ & $\mathrm{C} 4$ & $\mathrm{C} 5$ & $\mathrm{C} 6$ \\
\hline Bahrain & 2.67 & 2.72 & 3.02 & 2.86 & 3.01 & 3.29 & 3.14 & 3.10 & 3.33 & 3.38 & 3.32 & 3.58 \\
\hline Kuwait & 2.73 & 3.02 & 2.63 & 2.80 & 2.66 & 3.37 & 2.83 & 2.92 & 3.62 & 2.79 & 3.16 & 3.51 \\
\hline Oman & 2.87 & 3.16 & 3.30 & 3.05 & 2.97 & 3.80 & 2.76 & 3.44 & 3.35 & 3.26 & 3.09 & 3.50 \\
\hline Qatar & 3.00 & 3.38 & 3.75 & 3.42 & 3.56 & 3.70 & 3.55 & 3.57 & 3.58 & 3.54 & 3.50 & 3.83 \\
\hline Saudi Arabia & 2.66 & 3.11 & 2.99 & 2.86 & 3.17 & 3.30 & 2.69 & 3.24 & 3.23 & 3.00 & 3.25 & 3.53 \\
\hline \multirow[t]{2}{*}{ UAE } & 3.63 & 4.02 & 3.85 & 3.92 & 3.96 & 4.38 & 3.84 & 4.07 & 3.89 & 3.82 & 3.91 & 4.13 \\
\hline & \multicolumn{6}{|c|}{2014} & \multicolumn{6}{|c|}{2012} \\
\hline Country & $\mathrm{C} 1$ & $\mathrm{C} 2$ & $\mathrm{C} 3$ & $\mathrm{C} 4$ & $\mathrm{C} 5$ & C6 & $\mathrm{C} 1$ & $\mathrm{C} 2$ & $\mathrm{C} 3$ & $\mathrm{C} 4$ & $\mathrm{C} 5$ & C6 \\
\hline Bahr & 3.29 & 3.04 & 3.04 & 3.04 & 3.29 & 2.80 & 2.67 & 3.08 & 2.83 & 2.94 & 3.42 & 3.42 \\
\hline Kuwait & 2.69 & 3.16 & 2.76 & 2.96 & 3.16 & 3.39 & 2.73 & 2.82 & 2.68 & 2.68 & 2.98 & 3.11 \\
\hline Oman & 2.63 & 2.88 & 3.41 & 2.84 & 2.84 & 3.29 & 3.10 & 2.96 & 2.78 & 2.73 & 2.59 & 3.17 \\
\hline Qatar & 3.21 & 3.44 & 3.55 & 3.55 & 3.47 & 3.87 & 3.12 & 3.23 & 2.88 & 3.25 & 3.50 & 4.00 \\
\hline Saudi Arabia & 2.86 & 3.34 & 2.93 & 3.11 & 3.15 & 3.55 & 2.79 & 3.22 & 3.10 & 2.99 & 3.21 & 3.76 \\
\hline UAE & 3.42 & 3.70 & 3.20 & 3.50 & 3.57 & 3.92 & 3.61 & 3.84 & 3.59 & 3.74 & 3.81 & 4.10 \\
\hline
\end{tabular}

Since the CRITIC and MABAC methods use the same data normalization, the first step is the same for both methods and represents the normalization of the initial decision matrix (Table 3). All criteria are of benefit type and expression 2 or 6 is used.

After this step, the specific steps of the CRITIC and the MABAC methods are applied. Since it is necessary to calculate the weights of the criteria at the first place, the steps in the CRITIC method are explained first (Table 4). After the normalization, the values of standard deviation and correlation coefficient are calculated. After that step, the amount of information and the weights of the criteria are determined.

Table 3. Normalized decision matrix for LPI 2018

\begin{tabular}{lcccccc}
\hline & C1 & C2 & C3 & C4 & C5 & C6 \\
\hline Bahrain & 0.01 & 0.00 & 0.32 & 0.05 & 0.27 & 0.00 \\
Kuwait & 0.07 & 0.23 & 0.00 & 0.00 & 0.00 & 0.07 \\
Oman & 0.22 & 0.34 & 0.55 & 0.22 & 0.24 & 0.47 \\
Qatar & 0.35 & 0.51 & 0.92 & 0.55 & 0.69 & 0.38 \\
Saudi Arabia & 0.00 & 0.30 & 0.30 & 0.05 & 0.39 & 0.01 \\
UAE & 1.00 & 1.00 & 1.00 & 1.00 & 1.00 & 1.00 \\
\hline
\end{tabular}


Table 4. Steps in CRITIC method

\begin{tabular}{|c|c|c|c|c|c|c|}
\hline & C1 & C2 & C3 & C4 & C5 & C6 \\
\hline \multirow[t]{2}{*}{ ST.DEV } & 0.380 & 0.339 & 0.387 & 0.393 & 0.358 & 0.387 \\
\hline & C1 & $\mathrm{C} 2$ & C3 & $\mathrm{C} 4$ & $\mathrm{C} 5$ & $\mathrm{C} 6$ \\
\hline \multirow{7}{*}{ Correlation } & 1.000 & 0.955 & 0.811 & 0.972 & 0.858 & 0.965 \\
\hline & 0.955 & 1.000 & 0.792 & 0.942 & 0.861 & 0.925 \\
\hline & 0.811 & 0.792 & 1.000 & 0.915 & 0.917 & 0.822 \\
\hline & 0.972 & 0.942 & 0.915 & 1.000 & 0.935 & 0.933 \\
\hline & 0.858 & 0.861 & 0.917 & 0.935 & 1.000 & 0.784 \\
\hline & 0.965 & 0.925 & 0.822 & 0.933 & 0.784 & 1.000 \\
\hline & $\mathrm{C} 1$ & $\mathrm{C} 2$ & $\mathrm{C} 3$ & C4 & $\mathrm{C} 5$ & C6 \\
\hline \multirow[t]{2}{*}{$C_{j}=\sigma_{j} \sum_{k=1}^{m}\left(1-r_{j k}\right)$} & 0.167 & 0.178 & 0.288 & 0.119 & 0.231 & 0.221 \\
\hline & C1 & $\mathrm{C} 2$ & C3 & $\mathrm{C} 4$ & $\mathrm{C} 5$ & C6 \\
\hline$w$ & 0.138 & 0.148 & 0.240 & 0.099 & 0.192 & 0.183 \\
\hline
\end{tabular}

The same procedure is performed for other time periods, and individual weights are determined. To obtain one weight for the observed periods, the average weights are calculated. Based on the obtained weights, one can conclude that criterion C3 has the highest importance $(\mathrm{w}=0.238)$, while criterion $\mathrm{C} 4$ has the least importance $(\mathrm{w}=$ $0.120)$.

Table 5. Weights of criteria by observed time periods

\begin{tabular}{lcccccc}
\hline & C1 & C2 & C3 & C4 & C5 & C6 \\
\hline 2012 & 0.265 & 0.091 & 0.147 & 0.090 & 0.215 & 0.191 \\
2014 & 0.189 & 0.124 & 0.285 & 0.103 & 0.124 & 0.174 \\
2016 & 0.136 & 0.179 & 0.279 & 0.187 & 0.119 & 0.101 \\
2018 & 0.138 & 0.148 & 0.240 & 0.099 & 0.192 & 0.183 \\
\hline$w$ & 0.182 & 0.136 & 0.238 & 0.120 & 0.163 & 0.162 \\
\hline
\end{tabular}

After the weights have been calculated, the steps of the MABAC method are applied and the GCC countries are ranked according to the LPI indicators. After the initial decision matrices are normalized (Table 3), this matrix is aggravated (expression 8). After this, the average value of the criteria is calculated, which represents the expression of determination of the approximate border area matrix. The geometric mean is used here. The next step is focused to determine the distance of the alternatives from the arithmetic mean (Table 6) and to calculate the sum of these values. Based on the value, the ranking of alternatives is determined. The best alternative is the one that has the greatest value of $\tilde{S}_{i}$ and vice versa. The obtained results have shown that the UAE has the best LPI indicators, followed by Qatar, while Kuwait has the worst LPI indicators. In the same way, the calculation of the value of the MABAC method and the ranking of orders for the observed time periods is performed. 
Logistics Performances of Gulf Cooperation Council's Countries in Global Supply Chains

Table 6. Alternatives distance and the result of MABAC method

\begin{tabular}{lrrrrrrrr}
\hline & C1 & \multicolumn{1}{c}{ C2 } & \multicolumn{1}{c}{ C3 } & \multicolumn{1}{c}{ C4 } & \multicolumn{1}{c}{ C5 } & \multicolumn{1}{c}{ C6 } & \multicolumn{1}{c}{$\tilde{S}_{i}$} & Rank \\
\hline Bahrain & -0.020 & -0.036 & -0.015 & -0.013 & -0.005 & -0.028 & -0.117 & 5 \\
Kuwait & -0.009 & -0.005 & -0.091 & -0.019 & -0.049 & -0.016 & -0.188 & 6 \\
Oman & 0.017 & 0.010 & 0.039 & 0.007 & -0.010 & 0.048 & 0.113 & 3 \\
Qatar & 0.042 & 0.033 & 0.127 & 0.047 & 0.064 & 0.034 & 0.346 & 2 \\
Saudi Arabia & -0.022 & 0.005 & -0.021 & -0.013 & 0.015 & -0.026 & -0.062 & 4 \\
UAE & 0.160 & 0.100 & 0.146 & 0.100 & 0.114 & 0.135 & 0.755 & 1 \\
\hline
\end{tabular}

The results have shown that the UAE has the best LPI indicators for the entire observed time period, while Kuwait has the worst LPI indicators for 3 years (2018, 2014, 2012), and Saudi Arabia has the worst LPI indicators in 2016. Based on these findings, one can conclude that the UAE has the best logistic indicators, thus suggesting that this country provides the best solution for establishing a logistical center in the GCC region.

Table 7. Ranking of GCC countries using LPI indicators for the period 2012-2018

\begin{tabular}{lrrrrrrrr}
\hline \multirow{2}{*}{ Countries } & \multicolumn{2}{c}{2018} & \multicolumn{2}{c}{2016} & \multicolumn{2}{c}{2014} & \multicolumn{2}{c}{2012} \\
& \multicolumn{1}{c}{$\tilde{S}_{i}$} & Rank & \multicolumn{1}{c}{$\tilde{S}_{i}$} & Rank & \multicolumn{1}{c}{$\tilde{S}_{i}$} & Rank & \multicolumn{1}{c}{$\tilde{S}_{i}$} & Rank \\
\hline Bahrain & -0.117 & 5 & 0.021 & 3 & -0.003 & 4 & 0.003 & 4 \\
Kuwait & -0.188 & 6 & -0.063 & 4 & -0.163 & 6 & -0.198 & 6 \\
Oman & 0.113 & 3 & -0.072 & 5 & -0.133 & 5 & -0.118 & 5 \\
Qatar & 0.346 & 2 & 0.350 & 2 & 0.479 & 2 & 0.264 & 2 \\
Saudi Arabia & -0.062 & 4 & -0.140 & 6 & 0.004 & 3 & 0.149 & 3 \\
UAE & 0.755 & 1 & 0.758 & 1 & 0.487 & 1 & 0.738 & 1 \\
\hline
\end{tabular}

\section{Analysis of the results}

In order to confirm the results obtained using the combination of MABAC and CRITIC methods, the ranking of alternatives for all observed periods was performed using the methods: SAW Simple Additive Weighting technique, ARAS (Additive Ratio ASsessment), WASPAS (Weighted Aggregated Sum Product ASsessment), TOPSIS (Technique for Order Performance by Similarity to Ideal Solution) and MARCOS (Measurement Alternatives and Ranking according to the COmpromise Solution). This represents the first step in analyzing the results. The second step is to examine the sensitivity analysis against the change in weight criteria.

Examination of the reliability of the results obtained by applying other methods showed that there is no deviation in the ranking of GCC countries according to LPI indicators. Only for the indicators for 2014 there is a small deviation in the use of the TOPSIS method. According to the results of this method, Qatar has better results than the UAE for this year. This result was to be expected because the results using the MABAC method also showed that for this year there is a small difference between these two countries. Based on the obtained results, it can be concluded that the results obtained by the MABAC method are reliable and verified. 

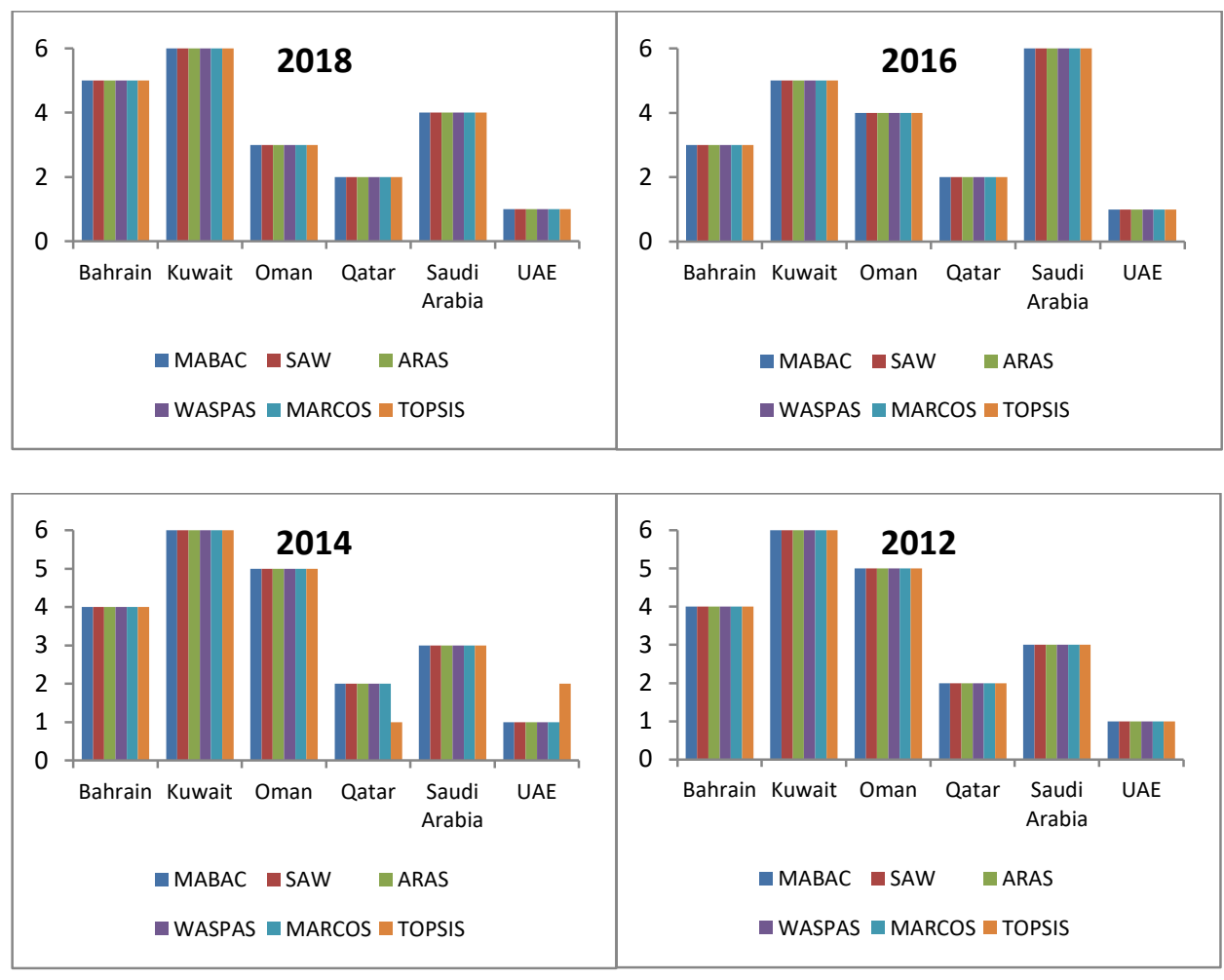

Figure 1. Results of GCC countries ranking according to LPI indicators for the period 2012-2018

The second step of our results analysis was to conduct a sensitivity analysis. When conducting a sensitivity analysis, it is examined how the change in the weights of subcriteria affects the ranking order of the alternatives (Puška et al., 2020). In accordance with this, scenarios were formed: the first scenario does not differentiate between criteria and gives the same importance to all criteria, the other scenarios give one of the criteria five times more importance compared to other criteria. Since there are 6 criteria used in this study, 7 scenarios have been formed in order to perform the sensitivity analysis.

Table 8. Scenarios in sensitivity analysis

\begin{tabular}{lcccccc}
\hline & C1 & C2 & C3 & C4 & C5 & C6 \\
\hline Scenario 1 & 0.1667 & 0.1667 & 0.1667 & 0.1667 & 0.1667 & 0.1667 \\
Scenario 2 & 0.5000 & 0.1000 & 0.1000 & 0.1000 & 0.1000 & 0.1000 \\
Scenario 3 & 0.1000 & 0.5000 & 0.1000 & 0.1000 & 0.1000 & 0.1000 \\
Scenario 4 & 0.1000 & 0.1000 & 0.5000 & 0.1000 & 0.1000 & 0.1000 \\
Scenario 5 & 0.1000 & 0.1000 & 0.1000 & 0.5000 & 0.1000 & 0.1000 \\
Scenario 6 & 0.1000 & 0.1000 & 0.1000 & 0.1000 & 0.5000 & 0.1000 \\
\hline Scenario 7 & 0.1000 & 0.1000 & 0.1000 & 0.1000 & 0.1000 & 0.5000 \\
\hline
\end{tabular}

The sensitivity analysis has shown that the results for 2018 are the least sensitive to changes in the weight of the criteria. We found a change in rankings only in scenarios 3 and 7 in which Kuwait showed better results compared to Bahrain. This 
Logistics Performances of Gulf Cooperation Council's Countries in Global Supply Chains can be justified with the fact that Kuwait has better performances compared to Bahrain in the Infrastructure and International shipments indicators. The sensitivity analysis for 2016 has shown that the ranking does not change for the UAE and Qatar, while the ranking is changed for other countries. The highest oscillation we found for Kuwait was due to the fifth place in three scenarios, the sixth place in three scenarios, and the third place in one scenario. Saudi Arabia also took the sixth place in 3 scenarios, and the fifth place in 3 scenarios. Oman has ranked as sixth in one scenario. Bahrain took the third place in five scenarios and the fourth place in two scenarios.

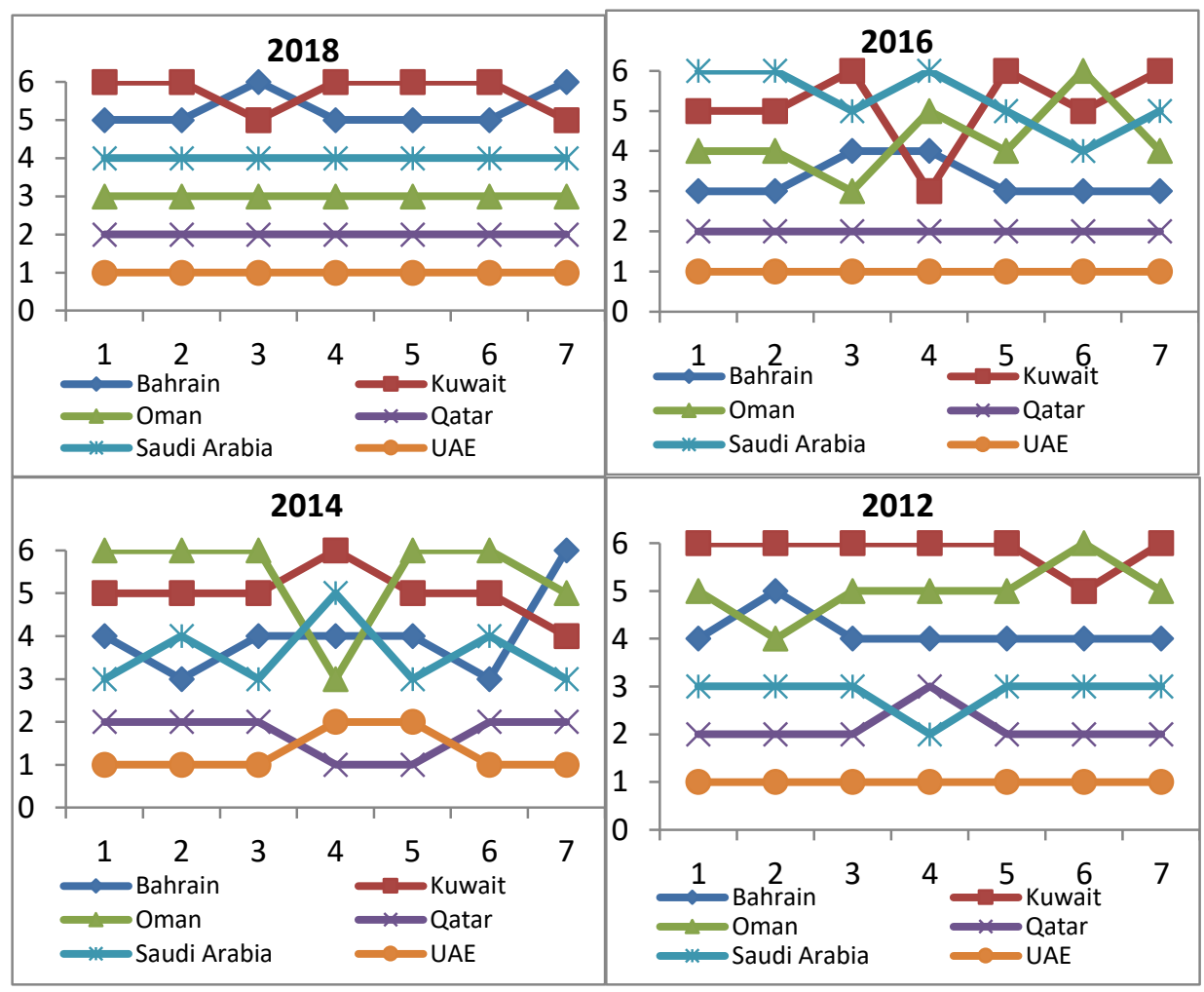

Figure 2. Results of sensitivity analysis

The sensitivity analysis for 2014 has shown the largest oscillations in the rankings. In almost all scenarios, the UAE took first place, only in 2014 Qatar took first place in two scenarios. The reason for this should be sought in the fact that Qatar had better performances in Services and Timeliness indicators compared to the UAE. Oman was ranked at the last place in 5 scenarios while Bahrain and Kuwait were ranked at the last place in one scenario. The sensitivity analysis for 2012 has shown less oscillation in the rankings. Saudi Arabia had a better performance in Services indicator compared to Qatar and is ranked better in 4 scenarios. Oman had a better performance of Customs indicator compared to Bahrain, and is ranked better ranked in scenario 2, while Kuwait had better performance of Tracking and tracing indicator compared to Oman and it is ranked better in scenario 6 .

The sensitivity analysis has shown that the LPI indicators were the most conflicting in 2014 and 2016, while in 2018 they were the least conflicting. This caused the least change in the ranking in sensitivity analysis. This analysis has also shown that the UAE 
has the best performances in LPI compared to other countries and it should be the first choice for a logistical center in this part of the world for trading and exporting goods globally.

\section{Discussion}

Nowadays, it is fully accepted in theory and practice that logistics centers are extremely important for global supply chains. They represent a significant strategic tool in international trade to reduce costs, reduce duration of supply process, increase sustainability of supply, but also increase overall competitiveness. To achieve these mentioned benefits, decision-makers must find the best locations for logistics centers that will improve competitiveness in global supply chains. This leads to the conclusion that the evaluation of different locations is very important for the effectiveness of the logistics centers.

We fully agree with the scholars who argue that selection of logistics center location should be based on the analysis of multiple criteria. Uyanik et al. (2018) presented different approaches that can be found in the literature by which different criteria are used in the analysis of the best location for a logistics center. As these scholars found, there is no single approach in the literature about these criteria. In avoiding these challenges about which criteria should be used, we followed what was proposed by Martí et al. (2017) who highlighted the benefits of the Logistics Performance Index (LPI). We support their thesis that LPI can help countries to get to know their business partners and to understand what should be adjusted to stay competitive in the logistics sector.

Our findings have shown that the United Arab Emirates leads the GCC region when it comes to logistics performance. In this sense, this country can be perceived as the best choice for the location of a logistics center that will allow the GCC region to be connected into a single supply chain. Several scholars indicated a highly developed and modern logistics infrastructure in this country (Jacobs and Hall,2007; Memedovic et al., 2008; Fernandes and Rodrigues, 2009; Ziadah, 2018). We are therefore fully convinced that this is one of the most important reasons why the UAE is the best ranked with our study.

As Jacobs and Hall (2007), we also believe that Dubai is the most important transportation hub in the region. Jebel Ali Port and Port Rashid, Dubai Airports, established free zones and regulatory reforms enabled Dubai and the UAE to become one of the most competitive transportation and logistics hubs in the GCC region. And development plans have yet to showcase new projects in Dubai that will further strengthen their competitive position as a logistics hub. While we write this paper, Dubai authorities announced full foreign share ownership of business in Dubai that will directly influence many foreign companies to locate their business in Dubai. Thus, this will lead to higher demand for logistics services in Dubai and the UAE. Furthermore, experience in logistics services makes an advantage when it comes to the position of the UAE through logistics performance. When we point to experience, we mean the fact that Dubai is home to world-renowned logistics and transportation companies such as DP World, Emirates Airlines Jebel Ali Free Zone (JAFZA), and Dubai World Central, that is also stressed out by Fernandes and Rodrigues (2009).

In addition to the rapid progress of the United Arab Emirates in the field of logistics, other countries in the GCC region have made significant achievements. The GCC countries have learned about the importance of logistics and have started to build exceptional logistics infrastructure that gives this region the opportunity to become a 
Logistics Performances of Gulf Cooperation Council's Countries in Global Supply Chains

logistics hub for trade between East and West. However, certain overlaps accompanied by costly infrastructure investments may lead to some other regions in Asia becoming more competitive in providing logistics services for global trade. Therefore, the GCC countries region need to improve coordination in the governance process of regional supply chains and to maintain and improve its position in global trade of commodities in the long run. This paper points out the importance of regional cooperation between GCC countries. As Coe at al. (2004) highlighted, we also support an integrated conceptual framework for 'globalizing' regional development. Thus, to integrate GCC as a single supply chain into global trade, the GCC countries should work on global production networks and share regional assets, such as logistics centers. In this regard, we support Durugbo et al. (2020) in their appeal to build long and profitable relationships with customers to replace traditionally fragmented approaches in the GCC region.

The Gulf Cooperation Council should have a special role in coordinating developmental activities of the region. The GCC administrative bodies should improve their governance capacity that is also indicated by Dadush and Falcao (2009) and create a joint development program for the region. The importance of joint development programs in the field of transport and logistics such as "New Silk Road" which should be the longest world road, or "TRACECA" which is an east-west transport corridor stretching from Central Asia to Europe, was indicated by KhassenovaKaliyeva et al. (2017) as highly important developmental programs to increase competitiveness of some countries or regions. Following similar patterns, the GCC can establish joint cooperation on the establishment of logistics centers that will serve in connecting the region into regional supply chains. Dadush and Falcao (2009) gave a very good proposal that Gulf Cooperation Council (GCC) must work to improve logistics and reduce non-tariff barriers to trade. Fernandes and Rodrigues (2009) went even more deeply by proposing policy makers to aggressively pursue the Monetary Union in the GCC region that certainly can facilitate establishing logistics networks more easily The countries of the GCC region need to accept the fact of growing competitors in the field of logistics, such as Singapore or some other Asian countries pointed by Fernandes and Rodrigues (2009). Thus, they should start to improve regional collaboration in the logistics chain.

What some authors such as Fernandes and Rodrigues (2009) point out, refers to the need to carefully analyze what they called the logistics skill gap amongst the workforce, including high rents and costs of operation in Dubai and the UAE. Despite the remarkable development of modern logistics infrastructure in this country, these issues need to be considered in order to maintain competitiveness. Only in this way can this location maintain its long-term logistics performance compared to competitors. Furthermore, some scholars such as Sundarakani et al. (2012) favored adopting IT solutions that can improve the effectiveness of logistics centers, but this should be followed with appropriate education of managers and employees to manage these systems in an efficient way.

What we also noticed is that locations that allow multimodal access to transport and logistics are much better positioned in the context of logistics performance. This has already been discussed by some authors (Fernandes and Rodrigues, 2009; Uyanik et al. 2018; Kazançoğlu et al. 2019). We have to agree with Fernandes and Rodrigues (2009) who indicated that Dubai represents an excellent world class integrated hub. This is where we find the main justification for the excellent results that Dubai and the United Arab Emirates have achieved through this study. We must not forget certain strategic issues. The countries of the GCC region, as stated by Memedovic et al. (2008) are still more focused on export of oil and similar energy resources. Therefore, we 
support the strategic directions of individual countries, including the United Arab Emirates, to put focus on other sectors and to develop their logistics capacities. We must not forget the historical fact that the cities located on the main transport routes developed the most. It is noticeable that the countries of the GCC region, especially the United Arab Emirates, accept this fact and take big steps in the development of logistics infrastructure. But, as Pham et al. (2017) suggested, this should be done in a systematic way by having master plans for the development of a logistics center system that will improve the practice of adequate selection and prioritizing of locations adequate for logistics centers. A crucial role at the regional level in the development of these plans and their coordination should be taken by the administrative bodies of the Gulf Cooperation Council.

\section{Conclusions}

The selection of an adequate location for a logistics center is one of the most important issues in the field of logistics operations management. In the literature, location selection is largely based on multi-criteria decision models. In our study we used data from the Logistics Performance Index developed by the World Bank and applied a hybrid multi-criteria approach based on the CRITIC and MABAC methods. Among the six GCC countries, we found that the United Arab Emirates are the best ranked in the observed period from 2012 to 2018. The exceptional logistics infrastructure built in this country certainly contributes to this result. In fact, the entire GCC region is taking big steps in the development of logistics infrastructure. Our study showed that Kuwait achieves poorer logistics performance compared to other countries in the region. Some countries during the observed period had certain oscillations in the movement of logistics performance, such as Saudi Arabia.

This study recommends that, based on logistics performance, the United Arab Emirates represent a country that can provide the best conditions for location of a regional logistics center that can connect the GCC region more efficiently into global supply chains. The significance of this study can be found in the study findings that indicates to GCC countries which areas should be improved to elevate overall logistics performance.

This study did not deal with a detailed analysis of the structure of exports by countries and product types. Therefore, transport and other relevant costs related to the inclusion of GCC countries in global supply chains through a single logistics center were not considered, which is one of the limitations of this study. Furthermore, this study focused on the logistics performances of individual GCC countries to find which country provides the best logistical conditions but did not search for suitable locations for logistics centers in these countries. Based on these limitations of the study, new areas are opened for future very interesting research endeavors.

In future research, it can be examined the role of LPI in the competitiveness of individual countries and determined how important a particular LPI criterion is for the competitiveness. Focus of future research can be also on other criteria and making decisions not with LPI only. However, the aim of this paper was to examine the trend of LPI for GCC countries to perceive which location provide best logistics performance for establishing logistics center. In addition, it is possible to consider other fuzzy methods when determining logistics centers and to establish hybrid methods. This research provides basic postulates for determining the location for logistics centers. 
Logistics Performances of Gulf Cooperation Council's Countries in Global Supply Chains

Author Contributions: Each author has participated and contributed sufficiently to take public responsibility for appropriate portions of the content.

Funding: This research received no external funding.

Conflicts of Interest: The authors declare that there is no conflict of interest.

\section{References}

Akkermans, H., Bogerd, P., \& Vos, B. (1999). Virtuous and vicious cycles on the road towards international supply chain management. International Journal of Operations \& Production Management.

Biswas, S., \& Anand, O. P. (2020). Logistics Competitiveness Index-Based Comparison of BRICS and G7 Countries: An Integrated PSI-PIV Approach. IUP Journal of Supply Chain Management, 17(2), 32-57.

Božanić, D., Tešić, D., \& Kočić, J. (2019). Multi-criteria FUCOM - Fuzzy MABAC model for the selection of location for construction of single-span bailey bridge. Decision Making: Applications in Management and Engineering, 2(1), 132-146.

Božanić, D.I., Pamučar, D.S., \& Karović, S.M. (2016). Application the mabac method in support of decision-making on the use of force in a defensive operation. Tehnika, 71(1), 129-136.

Chow, G., Heaver, T. D., \& Henriksson, L. E. (1994). Logistics performance, International journal of physical distribution \& logistics management.

Christopher, M. I. (2017). Logistics \& supply chain management. Fourth Edition, Prentice Hall

Coe, N., Hess, M., Yeung, H., Dicken, P. \& Henderson, J. (2004). Globalizing regional development: a global production networks perspective. Transactions of the Institute of British Geographers, 29(4), 468-484.

Dadush, U., \& Falcao, L. (2009). Regional arrangements in the Arabian Gulf. Universitäts-und Landesbibliothek Sachsen-Anhalt.

Diakoulaki, D., Mavrotas, G., \& Papayannakis, L. (1995). Determining objective weights in multiple criteria problems: The CRITIC method. Computers \& Operations Research, 22(7), 763-770.

Durugbo, C. M., Amoudi, O., Al-Balushi, Z., \& Anouze, A. L. (2020). Wisdom from Arabian networks: a review and theory of regional supply chain management. Production Planning \& Control, 1-17.

Elevli, B. (2014). Logistics freight center locations decision by using FuzzyPROMETHEE. Transport, 29(4), 412-418.

Fernandes, C., \& Rodrigues, G. (2009). Dubai's potential as an integrated logistics hub. Journal of Applied Business Research (JABR), 25(3).

Ibrahim, H. W., Zailani, S., \& Tan, K. C. (2015). A content analysis of global supply chain research. Benchmarking: An International Journal. 
Kazançoğlu, Y., Özbiltekin, M., \& Özkan-Özen, Y. D. (2019). Sustainability benchmarking for logistics center location decision. Management of Environmental Quality: An International Journal.

Khassenova-Kaliyeva, A. B., Nurlanova, N. K., \& Myrzakhmetova, A. M. (2017). Central Asia as a transcontinental transport bridge based on the transport and logistic system of the countries of this region. International Journal of Economic Research, 14(7), 365382.

Kishore, P., \& Padmanabhan, G. (2016). An integrated approach of fuzzy AHP and fuzzy TOPSIS to select logistics service provider. Journal for Manufacturing Science and Production, 16(1), 51-59.

Klassen. R. D. \& Whybark, D. C. (1994), “Barriers to the management of international operations", Journal of Operations Management, Vol. 11, pp. 385-96.

Kuo, M.S. (2011). Optimal location selection for an international distribution center by using a new hybrid method. Expert Systems with Applications, 38(6), 7208-7221.

Larson, P. D., \& Halldorsson, A. (2004). Logistics versus supply chain management: an international survey. International Journal of Logistics: Research and Applications, 7(1), 17-31

Li, Y., Liu, X., \& Chen, Y. (2011). Selection of logistics center location using Axiomatic Fuzzy Set and TOPSIS methodology in logistics management. Expert Systems with Applications, 38(6), 7901-7908.

Martí, L., Martín, J. C., \& Puertas, R. (2017). A DEA-logistics performance index. Journal of applied economics, 20(1), 169-192.

Meijboom, B.R. \& Vos, B. (1997). International manufacturing and location decisions: balancing configuration and co-ordination. International Journal of Operations \& Production Management, 17(7), 790-805.

Memedovic, O., Ojala, L., Rodrigue, J. P., \& Naula, T. (2008). Fuelling the global value chains: what role for logistics capabilities? International Journal of Technological Learning, Innovation and Development, 1(3), 353-374.

Onden, I., Acar, A. Z. \& Eldemir, F. (2016). Evaluation of the logistics center location using a multi-criteria spatial approach. Transport, 33(2), 322-334

Ou, C. W., \& Chou, S. Y. (2009). International distribution center selection from a foreign market perspective using a weighted fuzzy factor rating system. Expert Systems with Applications, 36(2), 1773-1782

Pamučar D., \& Ćirović G. (2015). The selection of transport and handling resources in logistics centers using Multi-Attributive Border Approximation area Comparison (MABAC). Expert Systems with Applications, 42(6), 3016-3028.

Pham, T. Y., Ma, H. M., \& Yeo, G. T. (2017). Application of Fuzzy Delphi TOPSIS to locate logistics centers in Vietnam: The Logisticians' perspective. The Asian Journal of Shipping and Logistics, 33(4), 211-219.

Puška, A., Beganović, A., \& Šadić, S. (2018). Model for investment decision making by applying the multi-criteria analysis method. Serbian Journal of Management, 13(1), 7 28. 
Logistics Performances of Gulf Cooperation Council's Countries in Global Supply Chains Puška, A., Stojanović, I., Maksimović, A., \& Osmanović, N. (2020). Evaluation software of project management used measurement of alternatives and ranking according to compromise solution (MARCOS) method. Operational Research in Engineering Sciences: Theory and Applications, 3(1), 89-102.

Rao, C., Goh, M., Zhao, Y. \& Zheng, J. (2015). Location selection of city logistics centers under sustainability. Transportation Research Part D: Transport and Environment, 36, 29-44.

Reyes, P., Raisinghani, M. S., \& Singh, M. (2002). Global supply chain management in the telecommunications industry: The role of information technology in integration of supply chain entities. Journal of Global Information Technology Management, 5(2), 4867.

Scully, J., \& Fawcett, S. E. (1993). Comparative logistics and production costs for global manufacturing strategy. International Journal of Operations \& Production Management, 13(12), 62-78.

Stević, Ž., Vesković, S., Vasiljević, M., \& Tepić, G. (2015). The selection of the logistics center location using AHP method. In 2nd Logistics International Conference, 86-91.

Sun, Y., Lu, Y., \& Zhang, C. (2019). Fuzzy Linear Programming Models for a Green Logistics Center Location and Allocation Problem under Mixed Uncertainties Based on Different Carbon Dioxide Emission Reduction Methods. Sustainability, 11(22), 6448.

Sundarakani, B., Tan, A. W. K., \& Over, D. V. (2012). Enhancing the supply chain management performance using information technology: some evidence from UAE companies. International Journal of Logistics Systems and Management, 11(3), 306324.

Uyanik, C., Tuzkaya, G., \& Oğuztimur, S. (2018). A literature survey on logistics centers' location selection problem. Sigma: Journal of Engineering \& Natural Sciences/Mühendislik ve Fen Bilimleri Dergisi, 36(1), 141-160.

Wang, B., Xiong, H., \& Jiang, C. (2014). A multicriteria decision making approach based on fuzzy theory and credibility mechanism for logistics center location selection. The Scientific World Journal, 2014, Article ID 347619

Wang, M. H., Lee, H. S., \& Chu, C. W. (2010). Evaluation of logistic distribution center selection using the fuzzy MCDM approach. International Journal of Innovative Computing, Information and Control, 6(12), 5785-5796.

Zarall, F., \& Yazgan, H. R. (2016). Solution of logistics center selection problem using the axiomatic design method. World Academy of Science, Engineering and Technology, International Journal of Computer, Electrical, 10(3), 547-553.

Zavadskas, E.K., Stević, Ž., Turskis, Z., \& Tomašević M., (2019). A Novel Extended EDAS in Minkowski Space (EDAS-M) Method for Evaluating Autonomous Vehicles. Studies in Informatics and Control, 28(3), 255-264.

Ziadah, R. (2018). Constructing a logistics space: Perspectives from the Gulf Cooperation Council. Environment and Planning D: Society and Space, 36(4), 666-682.

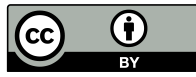

